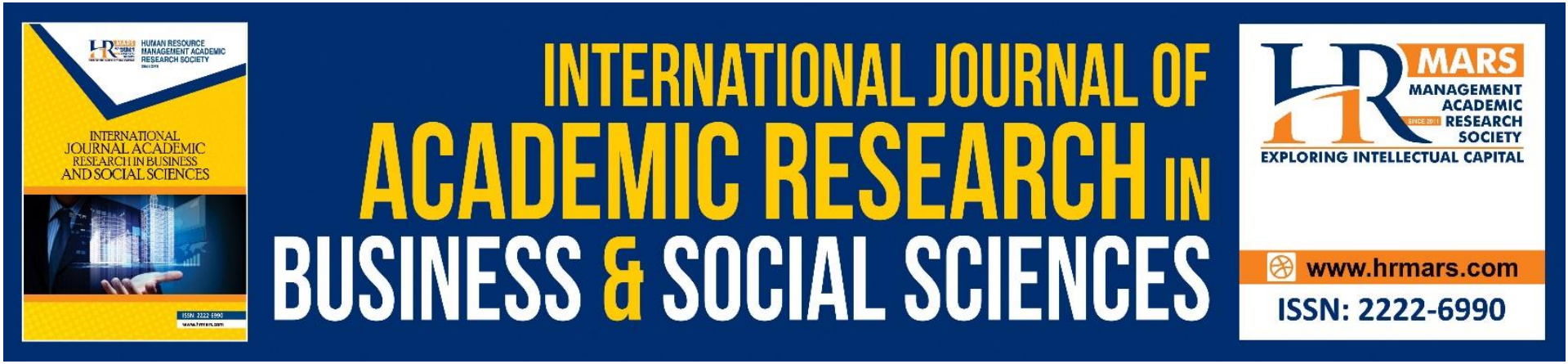

\title{
The Effect of Online Pornography on Pornography
} Motivation, Sexual Arousal and Gratification and its link to Tendencies towards Internet-Pornography-Viewing Disorder (IPD)

Aini Azeqa Ma'rof, Haslinda Abdullah, Hanina H. Hamsan, Mohd Shahrul Kamaruddin

To Link this Article: http://dx.doi.org/10.6007/IJARBSS/v11-i12/11934

DOI:10.6007/IJARBSS/v11-i12/11934

Received: 12 October 2021, Revised: 14 November 2021, Accepted: 28 November 2021

Published Online: 24 December 2021

In-Text Citation: (Ma'rof et al., 2021)

To Cite this Article: Ma'rof, A. A., Abdullah, H., Hamsan, H. H., \& Kamaruddin, M. S. (2021). The Effect of Online Pornography on Pornography Motivation, Sexual Arousal and Gratification and its link to Tendencies towards Internet-Pornography-Viewing Disorder (IPD). International Journal of Academic Research in Business and Social Sciences, 11(12), 2033- 2045.

\section{Copyright: @ 2021 The Author(s)}

Published by Human Resource Management Academic Research Society (www.hrmars.com)

This article is published under the Creative Commons Attribution (CC BY 4.0) license. Anyone may reproduce, distribute, translate and create derivative works of this article (for both commercial and non0-commercial purposes), subject to full attribution to the original publication and authors. The full terms of this license may be seen at: http://creativecommons.org/licences/by/4.0/legalcode

Vol. 11, No. 12, 2021, Pg. 2033- 2045

Full Terms \& Conditions of access and use can be found at http://hrmars.com/index.php/pages/detail/publication-ethics 


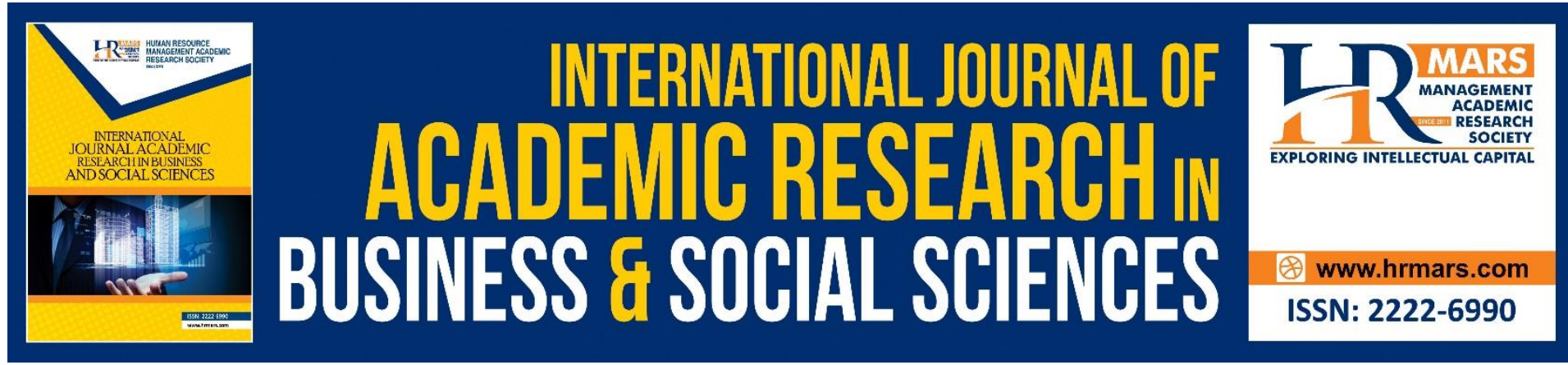

\title{
The Effect of Online Pornography on Pornography Motivation, Sexual Arousal and Gratification and its link to Tendencies towards Internet- Pornography-Viewing Disorder (IPD)
}

\author{
Aini Azeqa Ma'rof ${ }^{1}$, Haslinda Abdullah ${ }^{1}$, Hanina H. Hamsan ${ }^{1}$, \\ Mohd Shahrul Kamaruddin² \\ ${ }^{1}$ Faculty of Human Ecology, Universiti Putra Malaysia, 43400 Serdang, Selangor Darul Ehsan, \\ ${ }^{2}$ Institut Kemahiran MARA Kuching, Jalan Kemahiran, Off Jalan Sulatan Tengah, 93764 \\ Kuching, Sarawak. \\ Email: azeqa@upm.edu.my
}

\begin{abstract}
There has been a recent surge of research about behavioral addictions; some of them focus specifically on internet pornography addiction. However, despite all efforts, it is still unable to identify when engaging in this behavior becomes pathological. Thus, this research was conducted to identify the effects of online pornography consumption between pornography motivation, sexual arousal and gratification on the tendencies towards Internet PornographyViewing Disorder (IPD). A total of 202 online pornography users were involved in this study through snowball sampling technique based on an online questionnaire that were distributed to online channels such as e-mail lists, and social media websites (e.g., Twitter, Facebook and WhatsApp) that specifically targeted to online pornography users. Results shows that there was significant positive correlation of watching pornography on all sexual attitudes on the tendencies towards IPD. Meanwhile, having sexual arousal while viewing online pornography reported as the main indicator to IPD. The results showed effects of watching online pornography on pornography motivation, sexual arousal and gratification which can be considered having reinforcing effects for the users. Thus, the results are in line with theoretical assumptions on IPD's development, in which reinforcement received by Internetpornography use is related to cue-reactivity and craving reactions.
\end{abstract}

Keywords: Online Pornography, Pornography Motivation, Sexual Arousal, Sexual Gratification, Internet Pornography-Viewing-Online Disorder (IPD)

\section{Introduction}

Pornography is defined as printed or visual media that directly depicts sexual art with the intention of stimulating a person's sexual stimuli and desires (Sniewski et al., 2018). According to studies, internet pornography is one of the internet applications that poses a high risk of addiction (Griffiths, 2001). This is further reinforced by the increasing use of internet 
pornography. Internet pornography, in general refers to sexually motivate online actions such as accessing pornographic material, participating in sex-related online conversations or video calls, locating sex partners online, or acquiring sex-related information (Camilleri et al., 2018). These activities can be categorized into stimulus-only (example: watching pornography), stimulus-partners (example: sex chat), or non-stimulus activities (example: seeking information about pornography) (Shaughnessy et al., 2013).

Pornography is listed as a social issue. Over the last decade, access to pornography has shifted dramatically. Rapid access to different platforms or pornographic content is enabled by highspeed internet services (Ashton et al., 2019). The presence of online pornography has been shown to have a detrimental effect on a person's general functioning and well-being, including decreased sexual drive, erectile dysfunction, an increase proclivity for rape, and violence against women (Park et al., 2016). Thus, it is critical to identify the effects of watching or viewing pornographic materials on an individual's psychological and social well-being.

Addiction to pornography is no longer foreign in a world without borders and the speed of the internet. Meerkerk et al (2006) in their study stated that watching pornographic material has the greatest potential to make a person addicted and in turn will lead to internet pornography viewing disorder (Internet Pornography-Viewing Disorder, IPD). More worryingly, Pornhub, the world's largest pornographic video sharing platform revealed that in 2019, there was 42 billion visits to the site which led to 115 million visits a day. Pornhub also noted that the number of searchers also increased by 8.7 billion compared to 2018 . This figure shows that many among the individuals accessing these porn websites.

Online pornography addiction can affect individuals of various ages and backgrounds including adolescents (Hust et al., 2008), students (Shaughnessy et al., 2011), and adults of all ages (Daneback et al., 2005), as well as men and women (Camilleri et al., 2018). Nevertheless, men are more likely to access to online pornography (Short et al., 2012). Online pornography is further encouraged by its easy access, free or at a low cost, and use without requiring individual identities or without strict control (Cooper, McLoughlin, \& Campbell, 2000). However, there is a limited of empirical data on female internet pornography. Nevertheless, several studies on internet pornography among female demonstrate that female mostly use internet pornography applications for the purpose of sex chat (Danebak et al., 2005) and the user of internet pornography depends on individual attitudes towards pornography itself (Shaughnessy et al., 2011).

According to Davis' cognitive-behavioral model (Davis, 2001), pornography addiction starts from internet addiction itself or called internet pathology leading to exposure to pornographic materials. This repeated exposure eventually develops an affirmation to pornography and subsequently an addiction to online pornography. Moreover, according to Young (2008), being directly involved with online pornography and the sexual satisfaction received from watching pornography are the main causes underlying internet pornography addiction. Meanwhile, according to Brand et al (2011), there is a strong relationship between the level of sexual satisfaction derived from watching online pornography and the proclivity for internet pornography addiction. Psychologists argue that the rewards received from watching internet pornography in terms of sexual stimulation and satisfaction lead to the formation of cake-reactivity and the desire to repeatedly watch pornography resulting to pornography addiction. As a result, many studies now focus on the desire for sex and sexual stimulation as 
key indicators that increase a person's propensity to become addicted to online pornography. Therefore, it is important to deepen the effects of pornography addiction on one's well-being.

In addition, prolonged exposure to pornography will have a number of negative consequences for not only the individual's mental and physical well-being, but also for society. For example, exposure to pornography will make normal sexual behavior as a habit (Zillman, 1986), boredom, and sexual dissatisfaction among both men and women (Weaver \& Byers, 2013). Additionally, it is more dangerous when those who are accustomed to being exposed to pornography will be more open about extramarital sex and turn sexual activity into pleasurable activity (Lo \& Wei, 2005). A study by Zillman (2000) found that addiction to pornography makes a person more tolerant and "familiar" with sexually related materials, which motivates them to try new instruments and skills to satisfy their sexual demands.

\section{Online Pornography Addiction}

Nearly $82 \%$ of Malaysians have Internet access (Müller, 2020), and this technology has increase pornography use. The fledging body of research in this area are discussed controversially on the impact of Internet pornography (IP) which are both negative and positive. Specifically, studies on IP have been associated to many problems including financial (Short et al., 2012), intrapersonal relationships (Muusses et al., 2015), emotional problems (Laier \& Brand, 2016), and sexual dissatisfaction (Park et al., 2016). Meanwhile, studies also have found positive effects of internet pornography, including relieving stress (Laier \& Brand, 2016), decreasing boredom (Wegmann et al., 2018), feeling supported (Snagowski \& Brand, 2015), and increasing sexual knowledge (Grubbs et al., 2019). However, the harms that internet pornography may contribute to psychological defects especially in addiction is put into highlight.

The rising consumption of pornography among internet users has contributed to the development of IP addiction (Short et al., 2012). It allows the access to pornographic materials which increases the internet traffic even more. Internet pornography statistics reported that $67 \%$ of the internet traffic are those who are viewing PornHub - a pornographic video sharing and pornography website through smartphones alone. Meanwhile, $61 \%$ of the visitors are users from the age of 18 years old to 34 years old (Ropelato, 2014). Adding to this, 595, 482 hours has been spent in uploading pornography from the internet which reflects the addiction towards pornography materials.

\section{Pornography Motivation on IPD}

Grubbs, Wright, Braden, et al. (2018) conducted a meta-analysis of over 130 studies to demonstrate that pornography is most frequently consumed for pleasure-seeking purposes, that it is associated with an increase in casual or impersonal approaches to sexuality, and that it predicts more pleasure-oriented sexual behavior. This pleasurable sensation will result in cognitive deterioration, most notably addiction. While regular exposure to internet pornography has been linked to brain shrinkage, this is because the grey matter volume of the right caudate of the striatum shrinks with increased pornography consumption (Kühn \& Gallinat, 2014). Thus, considering the negative effect of online pornography addiction on one's mental health, it is crucial to explore the repercussion of online pornography as the drive or motivation to pornography addiction which further may develop the IPD. 


\section{Sexual Arousal and Gratification on IPD}

Sexual gratification or satisfaction is one of the terms used to describe IPD (Bradbury \& Karney, 2010). Researchers hypothesized in early investigations that pornography had caused harm and had a deleterious influence on sexual satisfaction (e.g., Zillman \& Bryant, 1988; Kenrick et al., 1989). This hypothesis was founded on two assumptions: first, that satisfaction is a subjective state influenced by comparisons to others and their experiences; and second, that pornographic actors are more sexually attractive and skilled than the majority of consumers and their partners, and that the gratifications associated with sex in pornography exceed those associated with sex in everyday life. However, in more recent studies, it has become a popular response provided by online pornography consumers when asked how pornography has influenced them (e.g., Kvalem et al., 2015).

Mulya and Hald (2014) discovered that internet pornography users expressed improved happiness with their sexual knowledge, skill, inter/intrapersonal relationships, attitude, efficacy, and even their life in general as a result of their usage of pornography. This is frequently reported among frequent and longer-term online pornography users who see such beneficial effects. However, psychologically, such impressions may represent a selfenhancement bias, a desire to minimize cognitive dissonance in order to explain their actions, or a psychological reaction to negative thoughts or sentiments that they should discontinue consuming the pornographic materials in issue (Bushman \& Huesmann, 2014).

Considering the consequences of pornography addiction, hence, this study aimed to investigate how internet pornography influences online pornography users in Malaysia, above 18 years old on their sexual activities that thus leads to IPD. Thus, this study focuses on the relationship between watching online pornography from the perspective of pornography motivation, sexual arousal and gratification on IPD. Specifically, the research objectives are:

1. To identify the participants' gender and hours of watching internet pornography.

2. To examine the relationship between pornography motivation, sexual arousal, and sexual gratification on IPD.

3. To determine the main factor that contribute to IPD.

\section{Method}

Procedure

Participants were recruited through e-mail lists social network sites (e.g. Twitter, Instagram and Facebook) and WhatsApp that mainly targeted to those that watch internet pornography. To ensure that the participants were among those internet pornography users, a snowballing technique has been used in order to identify individual or a group of people that watch pornography materials. The questionnaire description indicated explicitly that the online study investigates Internet-pornography use and that only Internet-pornography users were invited to participate. Individuals interested in participation were asked to answer the invitation on the google form and were then briefed and consent were given. The study was introduced as survey with three parts: 1) sociodemographic variables, 2) pornography motivation, sexual arousal and gratification, and 4) Internet Pornography Disorder (IPD).

\section{Participants}

The study focused on online pornography users who possessed the following criteria: (1) 18 years old and above, and (2) internet pornography uses in the past six months. The 
respondents were then described according to gender and hours of viewing online pornography.

\section{Measures}

Sociodemographic background. Necessary information such as age, gender, jobs, and hours of viewing pornography online were obtained. In this study, the sample were recruited following Laier and Brand's (2017) method which is through e-mail lists, social network sites (e.g. Twitter, Instagram and Facebook) and communication applications (e.g. WhatsApp).

Motivation, sexual arousal and gratification to online pornography were measured through Pornography Consumption Inventory developed by Reid, Li, Gilliland, Stein \& Fong (2011) which consist of 15 items and 3 items on the second component which focused on sexual and arousal gratification. A reliability test recorded $\alpha$ of 0.84 .

Tendencies on Internet Pornography-viewing Disorder (IPD) were measured using a short version of the Internet Addiction Test modified for sex (Laier et al., 2013). It is a 12-item questionnaire that will indicate the severity of addiction on a 5-point Likert scale of 1 (Never) to 5 (Always). Examples of items include, "How often do you try to hide how long you have been on the Internet sites?", "How often do you feel depressed, moody or nervous when you are off-line, which goes away once you are back on Internet sex sites?". The reliability was $\alpha$ $=.83$.

\section{Results}

Based on Table 1, it shows that majority of the respondents (85.7\%) age ranged between 18 -25 years old followed by $13 \%$ of age ranged between $25-30$ years old. This data particularly shows that majority of the internet pornography users are among the young adults. Meanwhile, in terms of gender, of 202 respondents, $55.7 \%$ are male and $44.4 \%$ are female that bring up to nearly an equal proportion of gender equivalent. For hours spent on viewing pornography in a weekly scale, majority of the respondents spent less than half an hour on viewing online pornography at $54.2 \%$. Alarmingly, $40.8 \%$ of the respondents spent at least 1 to 3 hours in viewing online pornography followed by $1.5 \%$ of the respondents spent at least 4 to 6 hours in viewing online pornography.

Table 1: Respondent's Sociodemographic Background

\begin{tabular}{cc}
\hline Variable & $\mathbf{N}(\%)$ \\
\hline Age & 85.7 \\
$18-25$ & 13.0 \\
$25-30$ & 1.0 \\
$31-40$ & 0.5 \\
41 above & 23.48 \\
Mean & 4.182 \\
Sd. & 19 \\
Min. & 69 \\
Max. & \\
\hline Gender & $\mathbf{N ( \% )}$ \\
\hline Male & 55.7 \\
Female & 44.3 \\
\hline
\end{tabular}




\section{Hours on Viewing Pornography \\ (Weekly)}

\begin{tabular}{cc}
\hline Hours viewing & $\mathbf{N}(\%)$ \\
\hline Less than a half hour & 54.2 \\
$1-3$ hours & 40.8 \\
$4-6$ hours & 1.5 \\
$>6$ hours & 3.5 \\
\hline
\end{tabular}

Meanwhile, Table 2 reported that pornography motivation showed a significant relationship on the tendencies towards IPD $(r=.52, \mathrm{p}<.05)$. Significant relationship also showed on sexual arousal; 1 ) while viewing online pornography and 2 ) the need to masturbate while watching online pornography $(r=.35, \mathrm{p}<.05 ; r=.35, \mathrm{p}<.05$ respectively). There was also a significant relationship between sexual gratification on the tendencies towards IPD where result reported $r=.24, p<.05$. Thus, these results indicate that internet pornography not only associated positively to pornography motivation, sexual arousal and gratification, but it also positively associated to IPD. Concerning the development of IPD, it has been argued that the medium's characteristics lead to the motivation to view pornography (Cooper et al., 2004). In terms of the user characteristics, it was hypothesised that certain personal qualities (e.g., high sexual excitability) may predispose persons to acquire IPD symptoms, and that these characteristics interact with pornographic-related cognitions (e.g., positive use expectations) (Laier \& Brand, 2016). Due to the reinforcing effects of watching pornography in terms of sexual enjoyment, conditioning processes should result in the development of cue-reactivity and subsequent seeking reactions to internal or external addiction-related cues. Additionally, the results of this study have been supported by previous studies which established the critical significance of sexual arousal and desire behaviours in IPD as a result of internet pornography watching (Brand et al., 2011, Laier et al., 2013, Rosenberg \& Kraus, 2014., Snagowski et al., 2015).

Table 2: The Relationship Between Pornography Motivation, Sexual Arousal and Gratification On The Tendencies Towards IPD.

\begin{tabular}{lcc}
\hline Variable & \multicolumn{1}{c}{ Tendencies towards IPD } \\
\cline { 2 - 3 } & $\boldsymbol{r}$ & $\boldsymbol{p}$ \\
\hline $\begin{array}{l}\text { Pornography Motivation } \\
\text { Sexual Arousal } \\
\text { (While watching internet }\end{array}$ & $0.517^{* *}$ & 0.000 \\
pornography) & $0.447^{* *}$ & 0.000 \\
$\begin{array}{l}\text { Sexual Arousal } \\
\text { (Need to masturbate while }\end{array}$ & \\
$\begin{array}{l}\text { watching internet pornography) } \\
\text { Sexual Gratification } \\
\text { (Satisfaction after an orgasm) }\end{array}$ & $0.352^{* *}$ & \\
\hline Note: *** Level of significant is at $p<0.001$ & & \\
& $0.241^{* *}$ & \\
& & \\
\end{tabular}

Note: ${ }^{* * *}$ Level of significant is at $\mathrm{p}<0.001$

Table 3 reported the main indicator that contributes to IPD. Overall, the model shows a significant with $R^{2}=0.310$. This shows that this model contributes $31 \%$ variance to IPD with $F$ $=2.445, p<.001$. Meanwhile, all four indicators contribute significantly towards IPD; 
pornography motivation $(B=0.009, \mathrm{p}<.001)$, sexual arousal (need to masturbate while viewing online pornography) $(B=-0.070, p<.001)$, sexual gratification $(B=-0.137, p<.001)$, with sexual arousal (while viewing online pornography) shows the strongest indicator that contribute to IPD $(\beta=0.544, p<.001)$. This study thus indicates that while the ability to become sexually aroused is a key factor in pleasurable sexual behavior, the presence of sexual excitatory stimuli may be sufficient to ensure that a sexual response will follow. Given that sexual arousal can be viewed as a primary and thus highly reinforcing stimulus (Georgiadis and Kringelbach, 2012) and in the context of conditioning processes in addiction (Berridge et al., 2009), it makes sense to assume that sexual arousal can be viewed as an unconditioned stimulus that can become associated with external and conditioned stimuli. This is consistent with research examining the neural correlates of perceived difficulties in managing sexual behaviours, which revealed a correlation between the activity of reward-related brain regions and subjectively reported yearning and the presentation of addiction-related sexual cues (Brand et al., 2016a, Voon et al., 2014). Thus far, the findings support the hypothesis that dysfunctional use of Internet pornography may be regarded a risk factor for developing IPD. The findings corroborate some basic assumptions of theoretical frameworks for Internet-use disorders, but these frameworks must be further defined in terms of the mechanisms underlying the development and maintenance of an addicted use of Internet pornography.

Table 3: Multiple Regression in Determining the Main Indicators Of Online Pornography Consumption On The Tendencies Towards IPD

\begin{tabular}{lcccc}
\hline Variable & \multicolumn{3}{c}{ Tendencies towards Internet Pornography-viewing } \\
& \multicolumn{4}{c}{ Disorder } \\
\cline { 2 - 5 } & B & SE. B & Beta, $\boldsymbol{\beta}$ & $\boldsymbol{p}$ \\
\hline $\begin{array}{l}\text { Pornography Motivation } \\
\text { Sexual Arousal (While viewing online } \\
\text { pornography) }\end{array}$ & 0.007 & 0.194 & 0.009 & 0.000 \\
$\begin{array}{l}\text { Sexual Arousal (Need to masturbate } \\
\text { while viewing online pornography) }\end{array}$ & 0.021 & 0.105 & 0.544 & 0.000 \\
$\begin{array}{l}\text { Sexual Gratification (Satisfaction after } \\
\text { an orgasm) }\end{array}$ & 0.038 & 0.052 & 0.070 & 0.000 \\
\hline $\begin{array}{l}\text { Adjusted R } \\
\text { F }\end{array}$ & 0.310 & & & 0.001 \\
\hline
\end{tabular}

\section{Discussion}

Pornographic materials are freely accessible due to their affordability, anonymity, and accessibility. Pornography, as a (mis)interpretation of sexuality, affects one conception of sexual relations, affecting both sexual attitudes and behavior. According to the results, addiction to pornography is fueled by constant novelty. From a psychological standpoint, the brain is continuously seeking rewards, and that general genres of pornography may no longer surprise the brain, leading it to seek out other genres of pornography that are stronger and more hard-core in order to maintain that reward mechanism (Wilson, 2016). Thus, regular consumption of online pornography will inevitably result in addiction and will endanger not just the individuals, but also society at large, as a result of unfavorable brain modifications and attitude changes. 
It is critical to recognize that a strong drive toward pornography motivation or a desire for sexual arousal and gratification may be the beginning of an addiction that progresses to IPD, as there is a significant relationship between pornography motivation, sexual arousal, and gratification, and IPD tendencies. Meanwhile, the fact that sexual arousal is the primary predictor of internet pornography consumption suggests that users consume pornography obsessively in order to elicit arousal. The need to receive or feel sexual stimulation compels users to read and consume online pornography at the expense of other crucial daily responsibilities.

\section{The Effect of Hours Viewing Internet Pornography on Individual Psychology}

Understanding the psychological impacts of pornography is critical for overcoming the detrimental effects of pornography on a person's mental and physical health. There have been over 90 research linking mental and emotional health to the fluctuating effects of watching pornography. These adverse effects include mental confusion, social anxiety to depression and recollection of action in porn videos. Studies shows that even three hours of pornographic film viewing each week can result in a considerable deterioration in cognitive function. When it comes to brain function, it has a direct impact on an individual's behavior and emotions. Event frequent discussions about pornography on social media will enhance the recurrence of watching pornography and addiction, which will disturb one's regular life patterns and cause one to lose sight of the goal of life.

According to a study conducted by Kuss and Griffiths (2012), an individual addicted to pornography might devote up to 16 hours per day to the activity. Additionally, the study underlines that it is not inconceivable that if an individual is addicted to internet pornography, they would spend a significant amount of time each day watching pornography which later will negatively affect their duties and responsibilities. There is no doubting that pornography addiction has the same, if not worse, consequences as drug or substance addiction. Meanwhile, Schenk (2009) discovered that the primary reason individuals watch pornography is to occupy their spare time and boredom as a result of the surplus time available. Thus, the more time spent watching pornography, the greater the likelihood of developing feelings of liking and addiction. In addition, study has shown that individuals who watch pornography for more than 6 hours per day show emotional instability, including feelings of depression, confusion, and exhaustion. In general, the longer users spend watching pornography, the larger its effect on their well-being and everyday tasks.

Relationship between Sexual Arousal and Gratification on Internet Pornography Addiction There is no denying that pornography does more harm than good especially when it can affect a person's behavior and emotions through uncontrolled thinking. Uncontrolled use of internet pornography can result in unstable emotions, stimulate the use of internet pornography, and even increase one's sexual arousal and satisfaction. Addiction to internet pornography will also lead to a mental disorder known as internet pornography disorder, which shares many of the same symptoms as online gaming addiction.

According to a study conducted by Laier and Brand (2017), individuals who are addicted to internet pornography exhibit strong emotional changes, such as feeling uncomfortable, constantly exhausted, and restless or aggressive, especially before and after watching pornography. The study also supports that those who continue to subscribe the internet 
pornography are unable to control their emotions, are prone to depression or emotional stress which in turn will lead to internet pornography disorders. Additionally, the study also found that after watching pornography, the participants emotional state increased, and sexual arousal decreased. This situation suggests that the use of internet pornography has a direct impact on the well-being of individuals.

Additionally, with the current availability of pornographic materials and the lack of exposure and conditions for viewing pornography especially online, this indirectly acts as reinforcement and motivation to a person to continue watching pornography without restriction. In fact, according to Wilson (2016), the main factor that drives a person to access pornography is the constant innovation showcased in internet pornography makes people motivated to continue watching pornography. These innovations include the latest sexual activities or styles that have never been tried or seen, especially if it is something that is interesting and can stimulate and satisfy their sexuality. These new materials will then shape a person's desire to watch pornography and at times it can lead to sexual abuse and violent sex.

Sexual stimulation and satisfaction are defined as an effective response as a result of a person's subjective assessment of whether it is something positive or negative related to one's sexual relationship (Ziaee et al., 2014). According to Kohut (2014), 55.17\% of the respondents stated that those who view pornography do so in order to be stimulated and experience sexual fulfillment. Pornographic materials helped them to enhance sexual feelings or emotions. Thus, the thrill and satisfaction experienced when viewing pornography will encourage repetition, resulting in internet pornography addiction. Even more concerning is the fact that not only pornography stimulates and satisfies individuals sexually during and after viewing, but also that pornography can enhance their drive to have sex. This is something to fear of since if the stimulus is channeled to the wrong place, it would be dangerous to other people who going to be their sexual victims.

\section{Conclusion}

The issue of pornography, pedophilia and sexual crimes have reached a crisis point in the country. The widespread use on internet pornography is a significant contributor to this problem, and it is difficult to curtail unless through the establishment of strong regulations and policies on pornography. Pornographic materials are available in a variety of genres to suit the tastes and preferences of consumers seeking innovation in their sexual activities. Meanwhile, Wilson (2012) argues that the human brain contains a "reward circuit" that produces the happy hormone called dopamine. Dopamine is secreted whenever the brain is rewarded with sex, touch, or even food. However, when the brain is exposed to natural rewards in an extreme way, the brain produces an abundance of the dopamine hormone, which causes a person to crave, or what is referred as in this context as pornography addiction. Therefore, addiction to internet pornography should not be underestimated, as it can progress to internet pornography disorder, which results in a decline in a person's mental health. Thus, online pornography must be addressed seriously, and psychologists and counsellors must devise efficient strategies for assisting those who are hooked, since it will have a detrimental effect on not just individuals, but also on families and society as a whole. 


\section{Reference}

Ashton, S., McDonald, K., \& Kirkman, M. (2019). What does 'pornography' mean in the digital age? Revisiting a definition for social science researchers. Porn Studies, 1 -25.

Berridge, K. C., Robinson, T. E., \& Aldridge, J. W. (2009). Dissecting components of reward:'liking','wanting', and learning. Current opinion in pharmacology, 9(1), 65-73.

Bradbury, T. N. \& Karney, B. R. (2010). Intimate relationships. New York: W. W. Norton.

Brand, M., Laier, C., Pawlikowski, M., Schächtle, U., Schöler, T., \& Altstötter-Gleich, C. (2011). Watching pornographic pictures on the Internet: Role of sexual arousal ratings and psychological-psychiatric symptoms for using Internet sex sites excessively. Cyberpsychology, Behavior, and Social Networking, 14(6), 371-377.

Brand, M., Young, K. S., Laier, C., Wölfling, K., \& Potenza, M. N. (2016). Integrating psychological and neurobiological considerations regarding the development and maintenance of specific Internet-use disorders: An Interaction of Person-AffectCognition-Execution (I-PACE) model. Neuroscience \& Biobehavioral Reviews, 71, 252266.

Bushman, B. J., \& Huesmann, L. R. (2013). Twenty-five years of research on violence in digital games and aggression revisited: A reply to Elson and Ferguson. European Psychologist, 19(1), 47-55.

Camilleri, C., Perry, J. T., \& Sammut, S. (2021). Compulsive internet pornography uses and mental health: A cross-sectional study in a sample of university students in the United States. Frontier Psychology, 11, 3870.

Cooper, A., McLoughlin, I. P., \& Campbell, K. M. (2000). Sexuality in cyberspace: Update for the 21st century. CyberPsychology \& Behavior, 3(4), 521-536.

Cooper, A., Delmonico, D. L., Griffin-Shelley, E., \& Mathy, R. M. (2004). Online sexual activity: An examination of potentially problematic behaviors. Sexual Addiction \& Compulsivity, 11(3), 129-143.

Daneback, K., Cooper, A., \& Månsson, S. A. (2005). An Internet study of cybersex participants. Archives of Sexual Behavior, 34, 321-328.

Davis, R. A. (2001). A cognitive-behavioral model of pathological Internet use. Computers in Human Behavior. 17(2), 187-195.

Georgiadis, J. R., \& Kringelbach, M. L. (2012). The human sexual response cycle: brain imaging evidence linking sex to other pleasures. Progress in Neurobiology, 98(1), 49-81.

Griffiths, M. (2001). Sex on internet: Observations and implications for internet sex addiction. The Journal of Sex Research, 38(4).

Grubbs, J. B., Wright, P. J., Braden, A. L., Wilt, J. A., \& Kraus, S. W. (2019). Internet pornogrpahy use and sexual motivation: a systematic review and integration. Annals of the International Communication Association, 43(2), 117-155.

Hust, S. J. T., Brown, J. D., \& L'Engle, K. L. (2008). Boys will be boys and girls better be prepared: The analysis if the rare sexual health messages in young adolescent's media. Mass Communication \& Society, 11(1), 3-23.

Kenrick, D. T., Gutierres, S. E., \& Goldberg, L. L. (1989). Influence of popular erotica on judgements of strangers and mates. Journal of Experimental Social Psychology, 25, 159-167.

Kohut, Taylor A., (2014). An Empirical Investigation of The Concept of Pornography. Electronic Thesis and Dissertation Repository. 2063.

Kühn, S., \& Gallinat, J. (2014). Brain structure and functional connectivity associated with pornography consumption: The brain on porn. JAMA Psychiatry, 71(7), 827-834. 
Kuss, D. J., \& Griffiths, M. D. (2012). Internet gaming addiction: A systematic review of empirical research. International Journal of Mental Health and Addiction, 10(2), 278296.

Kvalem, I. L., Traeen, B., \& Iantaffi, A. (2015). Internet pornogrpahy use, body idelas, and sexual self-esteem in Norwegian gay and bisexual men. Journal of Homosexuality, 63(4).

Laier, C., \& Brand, M. (2017). Mood changes after watching pornography on the Internet are linked to tendencies towards Internet-pornography-viewing disorder. Addictive Behaviors Reports, 5, 9-13.

Laier, C., \& Brand, M. (2016). Mood changes after watching pornography on the internet are linked to tendencies towards internet-pornography-viewing-disorder. Addictive Behaviours Reports, 5, 9-13.

Laier, C., Pawlikowski, M., Pekal, J., F. P., \& Brand, M. (2013). Cybersex addiction: Experienced sexual arousal when watching pornography and not real-life sexual contacts makes the difference. Journal of Behavioural Addictions, 2, 100-107.

Lo, V., \& Wei, R. (2005). Exposure to internet pornography and Taiwanese adolescents' sexual attitudes and behavior. Journal of Broadcasting and Electronic Media, 49(2), 221-237.

Meerkerk, G., Eijnden, R. J. J. M., \& Garretsen, H. F. L. (2006). Predicting compulsive Internet use: it's all about sex!. Cyberpsychology Behavior, 9(1), 95-103.

Müller, J. (2020). Malaysia: internet user penetration 2017-2023. Retrieved from https://www.statista.com/statistics/975058/internet-penetration-rate-in-malaysia/

Mulya, T. W., \& Hald, G. M. (2014). Self-perceived effects of pornogrpahy consumption in a sample of Indonesian University students. Media Psychology, 17, 78-101.

Muusses, L. D., Kerkhof, P., \& Finkenauer, C. (2015). Internet pornography and relationship quality: A longitudinal study of within and between partner effects of adjustment, sexual satisfaction and sexually explicit internet material among newly-weds. Computers in Human Behaviour, 45, $77-84$.

Park, B. Y., Wilson, G., Berger, J., Christman, M., Reina, B., Bishop, F., ... \& Doan, A. P. (2016). Is internet pornography causing sexual dysfunctions? A review with clinical reports. Behavioral Sciences, 6(3), 17.

Park, B. Y., Wilson, G., Berger, J., Christman, M., Reina, B., Bishop, F., Klam, W. P., \& Doan, A. P. (2016). Is internet pornography causing sexual dysfunctions? A Review with clinical reports. Behavioral Sciences, 6(3), 17, $11-25$.

Reid, R. C., Li, D., Gilliland, R., Stein, J. A., \& Fong, T. W. (2011). Reliability, validity, and psychometric development of the pornography consumption inventory in a sample of hypersexual men. Journal of Sex and Marital Therapy, 37(5), 359-385.

Ropelato, J. (2014) Internet pornography statistics. Retrieved from http://ministryoftruth.me.uk/wp-content/uploads/2014/03/IFR2013.pdf

Rosenberg, H., \& Kraus, S. (2014). The relationship of "passionate attachment" for pornography with sexual compulsivity, frequency of use, and craving for pornography. Addictive Behaviors, 39(5), 1012-1017.

Schenk, C. B. (2009). Pornography as a Leisure Behavior: An Investigation of Pornography Use and Leisure Boredom.

Shaughnessy, K., Byers, E. S., \& Walsh, L. (2011). Online sexual activity experience of heterosexual students: Gender similarities and differences. Archives of Sexual Behavior, 40, 419-27. 
Shaughnessy, K., Byers, E. S., Clowater, S. L., \& Kalinowski, A. (2014). Self-appraisals of arousaloriented online sexual activities in university and community samples. Archives of Sexual Behavior, 43(6), 1187-1197.

Short, M. B., Black, L., Smith, A. H., Wetterneck, C. T., \& Wells, D. E. (2012). A review of Internet pornography use research: Methodology and content from the past 10 years. Cyberpsychology, Behavior, and Social Networking, 15(1), 13-23.

Snagowski, J., \& Brand, M. S. (2015). Symptoms of cybersex addiction can be linked to both approaching and avoiding pornographic stimuli: results from an analog sample of regular cybersex users. Frontier Psychology, 6, 653.

Sniewski, L., Farvid, P., \& Carter, P. (2018). The Assessment and Treatment of Adult Heterosexual Men with Self-perceived Problematic Pornography Use: A review. Addictive Behaviors, 77, 217-224.

Voon, V., Mole, T. B., Banca, P., Porter, L., Morris, L., Mitchell, S., ... \& Irvine, M. (2014). Neural correlates of sexual cue reactivity in individuals with and without compulsive sexual behaviours. PloS one, 9(7), e102419.

Weaver, A. D., \& Byers, E. S. (2013) Eye of the Beholder? Sociocultural Factors in the Body Image and Sexual Well-Being of Heterosexual Women. International Journal of Sexual Health, 25:2, 128-147.

Wegmann, E., Ostendorf, S., \& Brand, M. (2018). Is it beneficial to use internetcommunication for escaping from boredom? Boredom proneness interacts with cueinduced craving and avoidance expectancies in explaining symptoms of internetcommunication disorder. PLOS ONE, 13(4).

Wilson, G. (2016) Eliminate chronic internet pornogrpahy use to reveal its effects. The Turkish Journal on Addiction, 3(2).

Wilson, G. (2016). Eliminate chronic internet pornography use to reveal its effects. Addicta: The Turkish Journal on Addictions, 23.

Young, K. S. (2008). Internet addiction: A new Clinical Phenomenon and its Consequences. American Behavioral Scientist, 48, 402-415.

Ziaee, T., Jannati, Y., Mobasheri, E., Taghavi, T., Abdollahi, H., Modanloo, M., \& Behnampour, N. (2014). The relationship between marital and sexual satisfaction among married women employees at Golestan University of Medical Sciences, Iran. Iranian Journal of Psychiatry And Behavioral Sciences, 8(2), 44.

Zillmann, D. (2000). Influence of unrestrained access to erotica on adolescents' and young adults' dispositions toward sexuality. Journal of Adolescent Health, 27(2), 41-44.

Zillmann, D., \& Bryant, J. (1986). Shifting preferences in pornography consumption. Communication Research, 13(4), 560-578.

Zillmann, D., \& Bryant, J. (1988). Pornography's impact on sexual satisfaction. Journal of Applied Social Psychology, 18, 438-453. 